\title{
Global slope performance index
}

\author{
T.D. Sullivan Pells Sullivan Meynink; and The University of New South Wales, Australia
}

\begin{abstract}
The evaluation of the performance and risk of excavated slopes is a complex esoteric task. Slope designers are always faced with gaps and uncertainties and in many cases the conditions as exposed are significantly different to the design predictions. In theory these issues may be addressed with detailed, rigorous investigations, analysis and models. But experience shows that even this approach is not always successful and surprises occur.
\end{abstract}

The paper presents a simple empirical system for predicting the current and future performance of excavated slopes. The system is the result of decades of experience with the design and evaluation of $100 \mathrm{~s}$ of slopes excavated for both mining and civil purposes. The examples include a very wide range of slope heights, slope angles, environments and material types. The experience also covers the full spectrum of operational performance, from stable slopes, to complete collapse.

In very simple terms three principal elements contribute to the stability of excavated slopes; intact strength, geological structure and groundwater. The Global Slope Performance Index (GSPI) is based on these three elements divided into five indices. These indices are each rated with a linear numerical scale and then combined into a simple algorithm, the GSPI.

The index has been benchmarked against actual slope performances and demonstrated by statistical analysis, which allows the likelihood of different slope performances and risk to be determined based on the Global Slope Performance Index.

\section{Introduction}

The evaluation of future slope performance and risk can be esoteric, complex and poses difficult questions in slope engineering. Slope designers, geotechnical engineers and mine operators are often faced with the conundrum of predicting the future performance and risk to the operations as the geological, hydrogeological and geotechnical conditions are revealed during excavation. In many instances these conditions are significantly different to those interpreted in the design models.

Mine slope design relies in large part on The Observational Method in order to manage the risk of unforseen outcomes impacting adversely on mine safety and economics (Terzaghi and Peck, 1967; Driscoll and Simpson, 2001). However, this method is not always successful. Many excavated slopes fail despite engineering studies and with seemingly acceptable design factors of safety. In addition many slopes give marginal performance, with ongoing risk of bench and multi-bench scale failures. Furthermore experience shows that slope movements can occur across a fairly wide range of factors of safety (Sullivan, 2007).

In theory these issues can be addressed by developing detailed rigorous structural geological, hydrogeological and geotechnical models; formulation of potential failure modes, stability analyses and computer modelling. However experience also shows that even with this rigorous design process, in many cases there are still significant gaps and uncertainties; and uncertainty is really at the heart of geotechnical engineering, particularly for large mine slopes (McMahon, 1985).

This paper presents a simple empirical system for predicting the current and future performance of excavated slopes. The system is called the Global Slope Performance Index (GSPI). The GSPI is based on decades of experience with the design and evaluation of 100s of slopes excavated for both mining and civil purposes. The examples include a very wide range of slope heights, slope angles, environments and material types. The experience also covers the full spectrum of operational performance, from stable 
slopes, which readily meet their design criteria, to complete collapse. Hence the GSPI is an empirical calibrated system for assessing current and future risks.

Experienced practitioners know that in very simple terms three principal elements contribute to the stability of excavated slopes; intact strength, geological structure and groundwater. The GSPI is based on these three elements divided into five indices. The complexities around geological structure are such that it is not possible to effectively capture the slope performance and risk with only one measure of geological structure, hence the increase from three to five indices. This increase allows the subdivision of geological structure into; rock mass character, controlling structure type and orientation of this structure relative to the slope orientation, all critical factors for stability. These indices are each rated with a linear numerical scale and then combined into a simple algorithm, the GSPI.

The indices were formalised by first selecting a few of the pre-requisites for stable slopes. These are the end members, those factors that when present, guarantee that steep stable slopes can be achieved. These factors are, strong intact rock strength, no major structures or pervasive structural fabric, massive rock and low groundwater pressures or levels. For each factor it was a straightforward task to clearly define the end members. These factors are all independent of each other and can be assessed reliably with simple guidelines. The understanding of the importance and roles of these pre-requisites have evolved throughout the author's career.

The GSPI has been in development for more than three decades and has been derived from consideration of actual stability problems as they were manifested in the field at all scales from 10's to 100's of metres. Over that time a conscious realisation developed that the same process of evaluation was being consistently followed on every occasion. The GSPI has been used in a subjective empirical way by the author for at least the last twenty years. This paper represents the formalisation of the process, together with the benchmarking that provides confidence in being able to use the GSPI in practice.

A key feature of the GSPI and probably the most important factor in terms of providing a readily useable reliable system is that it has been benchmarked against actual slope performance. This is supported by statistical analysis which allows the likelihood of different slope performance outcomes to be determined. The risks resulting from the predicted performance may then be readily assessed for the specific slope setting.

The GSPI is applicable for all mine and civil excavated slopes greater than about $30 \mathrm{~m}$ in height.

\section{$2 \quad$ Slope performance and risk}

Risk can be a difficult concept; albeit apparently simple in its common usage, it can mean many different things to different people; for example the chance or likelihood of danger, loss or injury from an adverse consequence or alternatively a hazard causing a risk.

The concept becomes much more complex when applied to geological problems. In the context of this paper and slope performance, risk is used in its generally accepted engineering definition of:

The combination of the chance of an event occurring (likelihood or probability) and the consequences if the event does occur.

In that context the 'event' is the occurrence of adverse geotechnical conditions which causes deformation of the slope.

However in this simple definition lies the crux of the difficulties encountered when attempting to assess risk with excavated slopes. Let's start with likelihood of the event occurring:

1. Firstly the 'event' has to be well understood, be able to be clearly identified beforehand and then adequately defined.

2. Secondly each of the possible contributing factors to the 'event' have to be identified, rated in terms of possible impact and then assessed in terms of their individual chance of occurrence. 
3. Thirdly it needs to be understood that in many circumstances the 'contributing factors' to the 'event':

a. May only be exposed at the small scale; or

b. May be entirely hidden from view; and/or

c. There may only be limited evidence available for them.

4. Fourthly the 'contributing factors' may include external loading conditions such as peak rainfall, which may require extrapolation into the future, for example the likelihood of an extreme rainfall event in the next five years. This occurrence then needs to be assessed in terms of possible impacts.

All of these items can be very difficult to judge without wide experience.

Assuming that the 'event' is correctly identified and all the contributing factors are known or have been assessed, so the likelihood of the 'event' has been established; what about the consequence? In this context, consequence is related to the slope performance. Slope performance covers a very wide spectrum of behaviour from small elastic movements, through cracking and deformation, to failure and complete collapse. These performances will all result in different levels of risk. Hence, what is our ability to adequately predict performance even if the 'event' does occur?

How then does the practitioner overcome these problems and reliably assess performance and hence the risk? Experienced practitioners will also be well aware how common it is for disagreements to occur between professionals, slope designers, reviewers and engineers, when asked to provide predictions of future performance and risk. The GSPI was developed, at least in part, in response to the relatively poor state of the art in terms of achievable accuracy with the mine slope design (Sullivan, 1994 and 2006).

Hartford (1998) provides a very useful discussion of risk and probability of failure in relation to dams. His discussion, while centred on dams, is equally useful for excavated slopes and elements of that discussion are included here. What is the probability of a slope failure during excavation? If a slope collapses during excavation then the performance is known, retrospectively, and the probability of failure is one (1.0). If another slope is excavated but it does not collapse during excavation, then once again the performance is known retrospectively, and the probability of failure is zero (0.0). However, what if the second slope which did not fail during excavation, showed marginal performance after excavation was completed, with ongoing movements and gradual deterioration; or alternatively did not collapse, but exhibited bench or some inter-ramp (IRA) scale instability? What then is the probability of failure, what is the performance and what is the risk? Can these aspects be accurately predicted or even predicted at all? Furthermore, even if a risk analysis was undertaken for these two slopes prior to excavation the results would not have been a zero or a one; our analysis tools are only capable of giving a number somewhere between 0 and 1 .

Hartford (1998) refers to the following definition of risk analysis:

"The prediction of events that have not yet happened." Royal Society (1992).

Probability allows risk assessments to be undertaken, because:

"A probability is a measure of the degree of confidence in a prediction, as dictated by the evidence, concerning the occurrence of an uncertain future event." Hartford (1998).

Within that context, the GSPI provides a way of having confidence in predictions, which is based on evidence and which provides a measure of both performance and risk even when these are apparently very difficult tasks to achieve using conventional approaches.

\section{Rock mass rating systems - a discussion}

The GSPI is essentially a rating system. However it is fundamentally different to many of the systems used in general slope design practice. 
In part because of the complexity of design in many rock masses, many attempts have been made to correlate rock slope design with rock mass parameters or slope design angles, using simple classification systems including:

- RMR - Rock mass rating (Bieniawski, 1976 and 1989)

- MRMR - Mining rock mass rating (Laubscher, 1977 and 1990)

- RMS - Rock mass strength (Selby, 1980)

- SMR - Slope mass rating (Romana, 1985)

- SRMR - Slope rock mass rating (Robertson, 1988)

- CSMR - Chinese system for SMR (Chen, 1995)

- GSI - Geological strength index (Hoek et al., 1995 and Marinos and Hoek, 2000)

- M-RMR - Modified rock mass classification (Ünal, 1996)

- BQ - Index of rock mass basic quality (Lin, 1998)

Most of these systems either use existing simpler systems, or logging parameters and are effectively 'built from the base up', by which is meant the particular authors selected a series of parameters that were believed to represent important contributors to a particular condition or result, but without rigorous prior calibration. For example the Rock Mass Rating (RMR) is a combination of strength, drill core Rock Quality Designation (RQD), spacing of joints and condition of joints. But some of the parameters are clearly not independent, for example RQD and joint spacing. Some of the systems were also developed for other uses, for example tunnelling or underground stability.

These empirical techniques have also been utilised to various extents in the design of slopes. Douglas (2002) provides a comprehensive comparison and evaluation of each method and the following discussion is based extensively on his work.

The majority of the methods require the determination of a basic rock mass rating, usually calculated by summing a number of ratings that account for intact rock strength, block size, defect condition and possibly groundwater. Some methods then adjust this value for defect orientation, excavation method, weathering, induced stresses and the presence of major planes of weakness. These ratings attempt to capture the main features that affect the rock mass shear strength and hence relate to the stability of slopes excavated in that rock mass.

The RMR is probably the most commonly used rock mass rating system for estimating rock mass strength. Although initially created for tunnels, it has been used for assessing the strength of rock masses for slope stability. Hoek et al. (1995) modified the RMR so as to make it more applicable to assessing the strength of rock masses, resulting in the Geological Strength Index (GSI). No corrections are made for joint orientation, which is assumed to be favourable, and it was considered joint orientation and water conditions should be assessed separately. Although commonly in practice this is not done.

The GSI is comprised of several components; intact rock strength, RQD; defect spacing and joint condition (water is already set to dry). All these components can be affected by scale and thus must be considered carefully when designing for very large rock masses. The GSI is currently the best available rock mass rating system for determining rock mass strengths. It is simple and easy to use, with the appropriate cautions.

Many authors have used these systems and attempted correlation with slope angles, including Laubscher (1977), Selby (1980), Romana (1985), Robertson (1988), Haines and Terbrugge (1991) and Orr (1992). Douglas discusses these systems and their successes and limitations in some detail and overall concludes:

"Most slopes will be structurally controlled and therefore a rock mass rating system will not be applicable for most slope design." Douglas (2002). 
Although a qualifier is added and this probably relates to low GSI rock masses, which will also generally have low resultant mass shear strengths:

"Empirical slope design using rock mass rating systems should only be considered for slopes in rock masses with GSI values lower than about 45 and only after any potential structurally controlled failures have been investigated." Douglas (2002).

The other limitation is that some of these systems were developed initially for structures that are at completely different scales to most mine slopes, for examples tunnels and caverns of 10 to $20 \mathrm{~m}$ in diameter, compared to excavated slopes hundreds of metres high. In addition most of the input parameters are scale dependent, for example, strength, RQD and defect spacing. This is a major limitation of these systems and a frequent source of error.

One of the benefits of the GSPI over these rating systems is that it requires the operator to directly evaluate the input parameters at the scale of the slope under consideration.

The GSPI is also not related to slope angle and makes no attempt to predict this. This statement will seem counter intuitive to many, because on face value the steeper the slope, potentially the more unstable the slope could be and hence the higher the risk. However the GSPI is designed for use with excavated slopes, at least at this stage. All of these excavated slopes have been the subject of a slope design. The presumption here is that the design has at least been good enough to result in a slope angle that is approximately accurate for the geotechnical conditions. The question then focuses on the rocks as exposed, how good was the slope design model and hence are problems likely to be generated. In the author's experience slope angle can be important, but it is usually a secondary or subsequent qualifying factor when assessing future performance. The GSPI is only an algorithm, derived empirically and used as a predictor of slope performance and risk.

\section{$4 \quad$ The accuracy of simple prediction systems}

This section describes the general body of knowledge and understanding that underpins an algorithm like the GSPI and why it was developed.

Psychology studies of predictions across a wide variety of fields have found that simple statistical formulas or algorithms were more accurate at prediction than subjective judgements of experienced professionals (Kahneman, 2011). The reasons offered include:

1. Experts often try to be clever, using complex considerations of many factors.

2. Experts are often overconfident in their intuitive judgements.

3. Complexity often reduces validity and in many situations simple combinations of factors are better.

4. The more complex the situation the more impact any inconsistencies have on the prediction accuracy.

5. Humans have been shown to be very inconsistent when judging complex situations.

However in order for the algorithm to be accurate as a predictor of performance it must be based on welldeveloped expertise. Expertise is simply a skill, but not a single skill, a collection of skills. The acquisition of expertise in complex tasks takes a long time to develop and is a slow and intricate process. The basic conditions for acquiring the skills necessary to become an expert are (Kahneman, 2011):

- An environment that is sufficiently regular to be predictable, that is fundamentally ordered situations.

- An opportunity to learn these irregularities through prolonged practice.

- Practice that includes quick, good quality feedback about the accuracy of the predictions. 
Most of us would have had the opportunity, sometime in our working lives, to have worked with experienced professionals who are able to very quickly assess a situation using what appears to be intuition; the act of knowing something without apparently knowing how. But an expert is someone who has acquired the ability to assemble familiar elements into new patterns. What was thought to be intuition is a mental process, where the situation has provided a cue(s) or clue, this cue gives the expert access to information stored in memory, and that information provides the answer. Intuition is simply recognition.

Simple weighted formulas based on statistics or common sense can be very good predictors of significant outcomes. Studies have shown that complex formulas are also not necessarily better: "the idea that a mechanical combination of a few variables could outperform the subtle complexity of human judgement...", will strike many practitioners as wrong, Kahneman (2011). Intuitively most professionals would believe that a multiple regression analysis of all possible factors leading to a formula based on a weighted combination of these factors would be a superior predictive tool, providing an optimal solution.

However, according to Dawes (1979) in Kahneman (2011):

"a selection of valid factors with standard ratings, combined with equal weighting of these factors, can be equally if not more accurate."

Large excavated slopes generally comprise many different technical factors each applying to various extents across a number of different technical disciplines. This can be a very complex or 'noisy' environment in which to predict performance. However statistical algorithms greatly outdo humans in noisy environments because they are more likely than humans to detect weakly valid cues and much more likely to maintain a modest level of accuracy by using the cues consistently.

These inconsistencies, Kahneman (2011) refers to them as biases in our thinking systems, also arise in part because there is now ready access to powerful software programs, which can provide detailed analysis of data and slopes. The answers are immediate and have the added weight of being provided by a computer. As such they have an apparent believability associated with the immediacy of the result and the understanding that this all powerful being, 'the computer', can do these complex calculations at warp speed which humans can't. The ability to quickly produce a result, often with brilliant graphics, only compounds this misconception.

However in most slope situations this is not the task. The task at hand is making predictions based on inadequate knowledge, with often only a simple understanding of all the issues; and major gaps and uncertainties. This is the role of the GSPI, to provide guidance with a focussed set of factual observations, that can be combined into a simple algorithm and which provides a calibrated body of experience about predicted outcomes.

\section{$5 \quad$ Global Slope Performance Index}

\subsection{Introduction}

The system was developed by firstly documenting those factors that have been used consistently by the author and which experience had shown were important for predicting slope performance. This list of factors was the result of decades of experience and had been constantly used and refined for a long time. Each factor was evaluated from experience into the basic sub-divisions that were generally used when assessing their relative contribution to the current and future slope performance.

Experience shows that in very simple terms, three key elements contribute to stability of excavated slopes; intact strength, geological structure and groundwater. The GSPI is based on these three elements. However the complexities around geological structure are such that it is not possible to effectively capture the performance and risk with only one measure of geological structure. Hence geological structure was further divided into three indices; rock mass character, controlling structure type, and orientation of this structure relative to the slope orientation. 
As noted above, the complexities of geological structure for slope design are such that three separate indices are required. These three structure indices are meant to broadly capture the following aspects:

- Rock mass character - This is traditionally used through GSI to provide a measure of rock mass strength. However, in this paper this index provides a measure of the level of disturbance to the intact rock and the structural complexity.

- Controlling structure type - A measure of the dominant structure type in the rock mass, as measured by continuity and or frequency of occurrence and or the frequency of structure intersections. However, the strengths of the different structure types are also important in this assessment.

- Orientation - In most rock slope engineering situations structure orientation relative to the slope is probably the dominant factor.

The elements selected had to be, as well as can be, independent of each other, and subdivisions had to be able to be assessed reliably, so they needed to be simple and readily understood. In order to facilitate use, existing categorisation system concepts have been used where practicable. The sub-divisions within each index were developed on a progressive scale from minor or unimportant to very important. In order for the system to operate effectively, it is important to assess each element individually in the set order, scoring each element one at a time, so as to try to overcome the innate biases in our intellectual systems, Kahneman (2011).

\subsection{Description}

The GSPI comprises five indices:

1. Intact rock strength, as indicated by the Uniaxial Compressive Strength (UCS).

2. Rock mass character.

3. Geological structure, namely the dominant or controlling structures in the rock mass.

4. The orientation of these structures relative to the slope.

5. The groundwater conditions and or groundwater response patterns.

Experience has shown that the intact rock strength is in nearly every instance the first question to be asked when assessing a slope. Hence the inclusion of this parameter at the start of the index is somewhat self-evident.

Mass strength is clearly important for stability, although this is not a fundamental component of the GSPI. However the deformation the rock mass has undergone in its history as measured by the degree of fracturing or structural disturbance to the rock mass is a fundamental component. Rock mass character can be a measure of many things, but in this index it mainly tries to account for the following elements:

- Rock mass deformation, as measured by the degree of structural disturbance or fracturing within the rock mass.

- The percentage of faults, shears and or clay filled or low strength structure planes that the rock mass contains.

- The structural complexity of the rock mass and how well this can be captured or modelled.

- The probability of encountering unknown or unexpected adverse geological structures or zones.

- Finally the likelihood of encountering unknown or unexpected conditions.

In addition the rock mass character aspect also relates indirectly to the complexity of the groundwater regime and its responses to loading events. As deformation increases the risks attached to encountering 
adverse low strength structures or zones also increases as does the likelihood of more complex hydrogeological conditions. The GSPI is a measure of risk and risk is about knowledge and uncertainty.

Identification of the dominant structures in a slope is also a key for assessing stability. This is potentially the most difficult index to get right and is a judgement exercise. It also requires the classification to be made at the scale of the planned slope, which some may also find to be a challenge. Simple descriptive guides are provided in the following sections for reference.

The orientation of structures relative to the slope is largely self-explanatory and the only issue that may arise is some debate over the classification divisions. But in this regard some comfort should arise from the analysis of the results.

The groundwater index is a combination of two elements firstly the level of groundwater and secondly the measured responses of the groundwater to rainfall runoff loading events. The level of groundwater could be a water table condition as measured by the height of the groundwater table or alternatively the pore pressures in the slope as a fraction of hydrostatic conditions, where both are assessed relative to slope height.

\subsection{The benefits of five indices}

The experience with failures of excavated slopes demonstrates that when significant problems develop there are usually a minimum of three significant contributing factors. Their relative contributions to the event may vary, but overall in nearly all cases there is at least that number of important factors.

The five indices in the GSPI have all been significant contributors to poor slope performance in a large number of events. However not every index was important in every case. Using a simple linear numerical scale of 1 to 5 (best to worst) the total allowable GSPI score is 25 . However because of the experience described above, in the case study database, the maximum scores are somewhat less than this.

Five equally weighted indices means that for any excavated slope with problems, any three of the five indices, results in a relatively high base score, which in combination with the other two indices results in a high total GSPI score.

\subsection{Importance of slope scale evaluation}

One of the common significant failings in the application of the rock mass strength categorisation systems is the seeming inability of many to effectively transpose the results from a length of core only metres in length to a visualisation that encompasses the full slope height.

The most important aspect of the GSPI system is to ensure it is evaluated for the full slope scale under consideration. Probably one of the most important exercises in mining and civil engineering for rock slopes is to carefully determine what the key geological structures for the slope scale under consideration are, Figure 1. This is the concept where all analysis of excavated slopes should commence and if this doesn't occur, then it is the author's experience that it will be difficult to arrive at the right answer. The difficulty with being able to summarise effectively at slope scale is compounded when the data is limited to cored holes or small exposures alone.

The author has often found it useful in these circumstances to simply draw the excavation to scale and then superimpose the various structures present also at their respective scales. This simple exercise will aid judgement.

\subsection{Intact strength}

\subsubsection{Introduction}

Strength is the first index of the GSPI to be determined. Experience has shown that even in a weak to very weak rock, quite steep, high (even up to inter-ramp scale), stable slopes can be achieved provided the rock 
is massive, with no significant major structural defects and the groundwater level or pressures are low. Hence fundamentally the intact rock strength is an essential index to determine. The relative importance of rock strength in the GSPI then decreases as the intensity of structural disturbance increases.

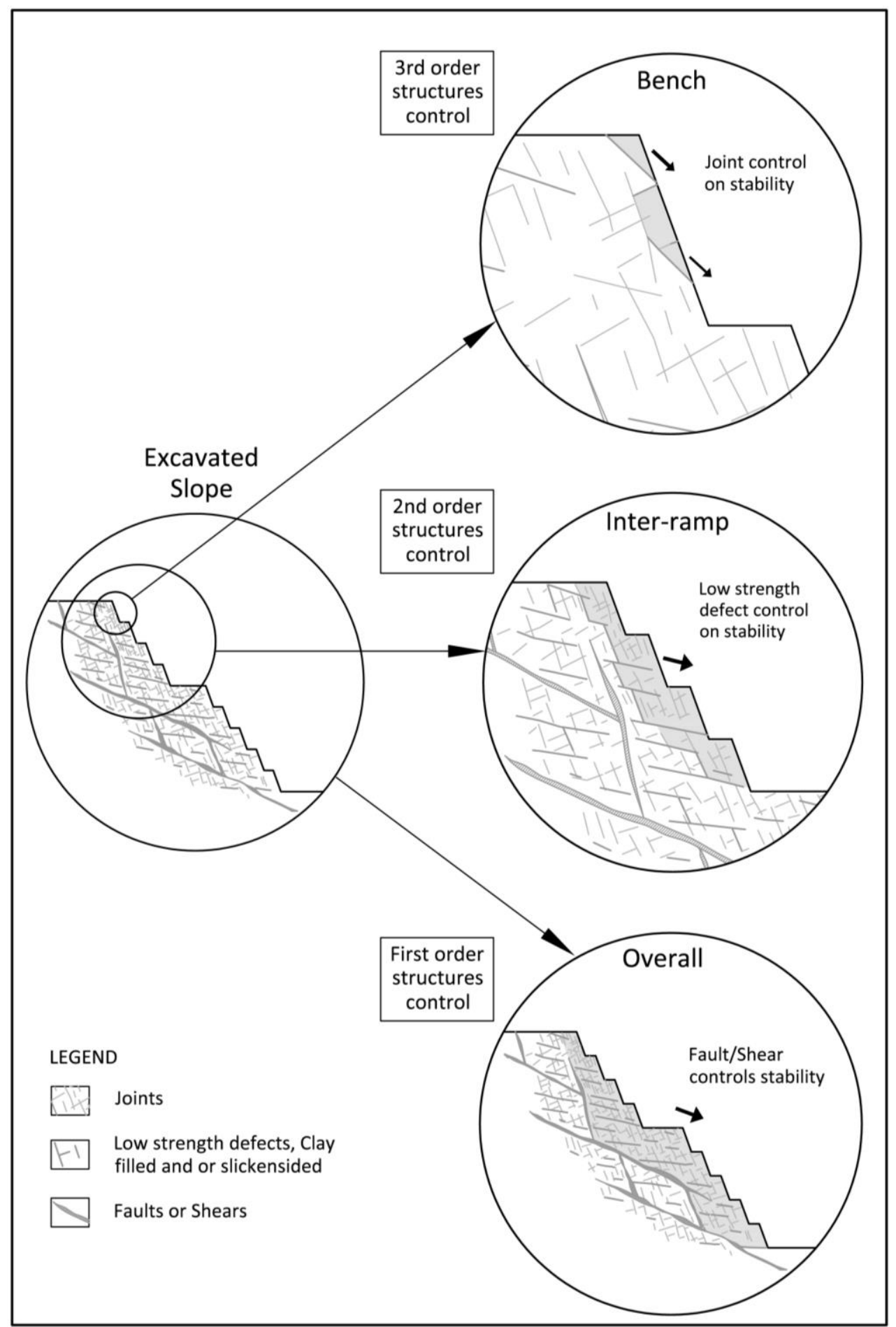

Figure 1 Slope scale and controlling defects

The strength index can be determined either by specific testing, UCS or Point Load Strength, or by empirical field methods. Although a word of caution if using Point Load Strengths at the lower end of the strength ranges, care is required to use the right multiplier when converting to UCS. A number of empirical classification systems for field estimation of UCS have been developed over the years, including ISRM (1978 and 2007), Attewell and Farmer (1975), CANMET (1977), Geological Society of London, Engineering Geology 
Working Group (1977) and Australian Standards (1993). Although broadly similar, in detail there are significant differences in the strength ranges and the field estimation techniques. These differences also appear to be driven at least in part by the general usage of each system. Duran (in press) provides a critical comparison of the various systems.

In order to facilitate ease of use of the GSPI, the strength rating is based initially on the ISRM system (1978 and 2007). However, because of the differences discussed above, the GSPI is calculated using two separate classifications:

- ISRM, which is weighted towards the higher end of the strength spectrum.

- An in house system, developed by Pells Sullivan Meynink (Duran, in press), which is weighted towards lower strength ranges.

When using either system, it is generally best to use the median rock mass strength for classification.

\subsubsection{Strength - ISRM system}

The classification is based generally on the ISRM (2007). However for this usage and because the GSPI is aimed mainly at rock, the soil categories are ignored and the rating for all soil strength material is combined into the first rock strength category R1. In addition the upper two high strength categories are combined and the boundary capped at greater than $100 \mathrm{MPa}$. This is because experience has shown that at these strengths the influence of strength on the overall slope performance is significantly reduced and performance is more dominated by structure.

The classification system is described in Table 1 and the GSPI scores are summarised in Table 2.

Table 1 Field estimates of UCS (after ISRM, 2007)

\begin{tabular}{|c|c|c|c|c|}
\hline ISRM Grade & Term & $\begin{array}{l}\text { UCS } \\
(\mathrm{MPa})\end{array}$ & $\begin{array}{l}\text { Is50 } \\
\text { (MPa) }\end{array}$ & Field Estimate of Strength \\
\hline R6 & Extremely strong & $>250$ & $>10$ & $\begin{array}{l}\text { Rock material only chipped under } \\
\text { repeated hammer blows, rings when } \\
\text { struck. }\end{array}$ \\
\hline R5 & Very strong & $100-250$ & $4-10$ & $\begin{array}{l}\text { Requires many blows of geological } \\
\text { hammer to break intact specimens. }\end{array}$ \\
\hline R4 & Strong & 50-100 & $2-4$ & $\begin{array}{l}\text { Hand held specimens broken by a single } \\
\text { blow of geological hammer. }\end{array}$ \\
\hline R3 & Medium strong & $25-50$ & $1-2$ & $\begin{array}{l}\text { Firm blow with geological pick indents } \\
\text { rock to } 5 \mathrm{~mm} \text {, knife just scrapes surface. }\end{array}$ \\
\hline R2 & Weak & $5-25$ & N/A & $\begin{array}{l}\text { Knife cuts material but too hard to shape } \\
\text { into triaxial specimens. }\end{array}$ \\
\hline R1 & Very weak & $1-5$ & N/A & $\begin{array}{l}\text { Material crumbles under firm blows of } \\
\text { geological pick, can be shaped with knife. }\end{array}$ \\
\hline Ro & Extremely weak & $0.25-1$ & N/A & Indented by thumbnail. \\
\hline
\end{tabular}


Table 2 GSPI score - ISRM strength categories

\begin{tabular}{clcc}
\hline ISRM Grade & Term & UCS (MPa) & GSPI Score \\
\hline R5/R6 & Extremely to very strong & $>100$ & 1 \\
R4 & Strong & $50-100$ & 2 \\
R3 & Medium strong & $25-50$ & 3 \\
R2 & Weak & $5-25$ & 4 \\
R1/R0 & Very weak & $<5$ & 5 \\
\hline
\end{tabular}

\subsubsection{Strength-Pells Sullivan Meynink system}

The system is based on the Pells Sullivan Meynink (PSM) system, which is weighted towards the lower strength ranges. These strengths are based on two existing systems:

- Australian Standard for Geotechnical Site Investigations, AS 1726-1993.

- CANMET Pit Slope Manual (1977).

However in this instance the soil categories are ignored and the rating for all soil strength material is combined into the first rock strength category, R1. The system is weighted towards the lower strength ranges in order to better account for the impacts of weathering and alteration on rock strengths and to adequately capture sedimentary rocks.

The classification system is described in Table 3 and the GSPI scores are summarised in Table 4.

Table 3 Field estimates of UCS - PSM system

\begin{tabular}{|c|c|c|c|}
\hline PSM Grade & Term & UCS (MPa) & Field Estimate of Strength \\
\hline R5 & Very high & $>80$ & $\begin{array}{l}\text { Specimen requires many blows of hammer end of } \\
\text { geological pick to fracture. }\end{array}$ \\
\hline R4 & High & $25-80$ & $\begin{array}{l}\text { Specimen requires more than one blow with hammer } \\
\text { end of geological pick to fracture. }\end{array}$ \\
\hline R3 & Medium & $10-25$ & $\begin{array}{l}\text { Cannot be scraped or peeled with a pocket knife. } \\
\text { Specimen can be fractured with a single firm blow of } \\
\text { hammer end of geological pick. }\end{array}$ \\
\hline R2 & Low & $3-10$ & $\begin{array}{l}\text { Can be peeled by a pocket knife with difficulty. Shallow } \\
\text { indentation made by firm blow of geological pick. }\end{array}$ \\
\hline R1 & Very low & $1.5-3$ & $\begin{array}{l}\text { Can be peeled by a pocket knife. Crumbles under firm } \\
\text { blows of geological pick. }\end{array}$ \\
\hline RO & Extremely low & $<1.5$ & $\begin{array}{l}\text { Thumbnail easily scratches; gentle blow with } \\
\text { geological pick leaves deep impression. }\end{array}$ \\
\hline
\end{tabular}


Table 4 GSPI score - PSM Strength categories

\begin{tabular}{clcc}
\hline PSM Grade & Term & UCS (MPa) & GSPI Score \\
\hline R5 & Extremely to very strong & $>80$ & 1 \\
R4 & Strong & $25-80$ & 2 \\
R3 & Medium strong & $10-25$ & 3 \\
R2 & Weak & $3-10$ & 4 \\
R1/R0 & Very weak & $<3$ & 5 \\
\hline
\end{tabular}

\subsection{Rock mass character}

The rock mass character is based loosely on the Geological Strength Index (GSI) concept (Marinos and Hoek, 2000). Experienced practitioners will recognise the basic concepts of the GSI system within Figure 2. It was considered by the author that because of the widespread acceptance of this system, it would assist in making the whole concept both more acceptable and more user friendly.

However the GSI system is a matrix with two axes:

- The vertical axis, which covers rock mass structure and the interlocking of rock pieces, which in effect is an indirect measure of Rock Quality Designation (RQD) or defect spacing.

- The horizontal axis, which captures the joint surface conditions and or joint surface character.

In order to be able to work effectively as a matrix, one needs to be able to use both axes somewhat independently. It would be very difficult in a simple linear numerical ranking scale to effectively capture both these factors.

Hence for simplicity and practical reasons, the two axes have been combined in the GSPI system. But this is not seen as a shortcoming, because experience shows that as the degree of deformation within rock mass increases, i.e. the rock mass moves from a 'massive' to a 'sheared' rock mass, the effective strength of the defect surfaces also reduces. This is partly recognised in the Hoek-Brown rock mass classification system (Marinos and Hoek, 2000); because the extreme outcome, at both the 'massive' and 'sheared' ends of the matrix, are classed as not applicable. Hence it is not possible to have rough to very rough defect surfaces in a sheared rock mass and similarly it is not possible to have slickensided and clay filled defect surfaces in a massive rock; at least not as the general design cases.

It is the author's experience that it is actually not geologically possible to have a 'blocky/disturbed/seamy' or 'laminated/sheared' rock mass that does not contain a significant percentage of slickensided, polished and or clay filled defects.

It is also worthwhile noting the assumptions that underlie the GSI classification, including:

- It does not apply to structurally controlled failures.

- The rock mass is isotropic.

- The rock mass is comprised of intact rock pieces separated by closely spaced joints.

- There is no preferred failure orientation.

- The GSI system should not be used when there is a dominant structural system in the rock mass. 


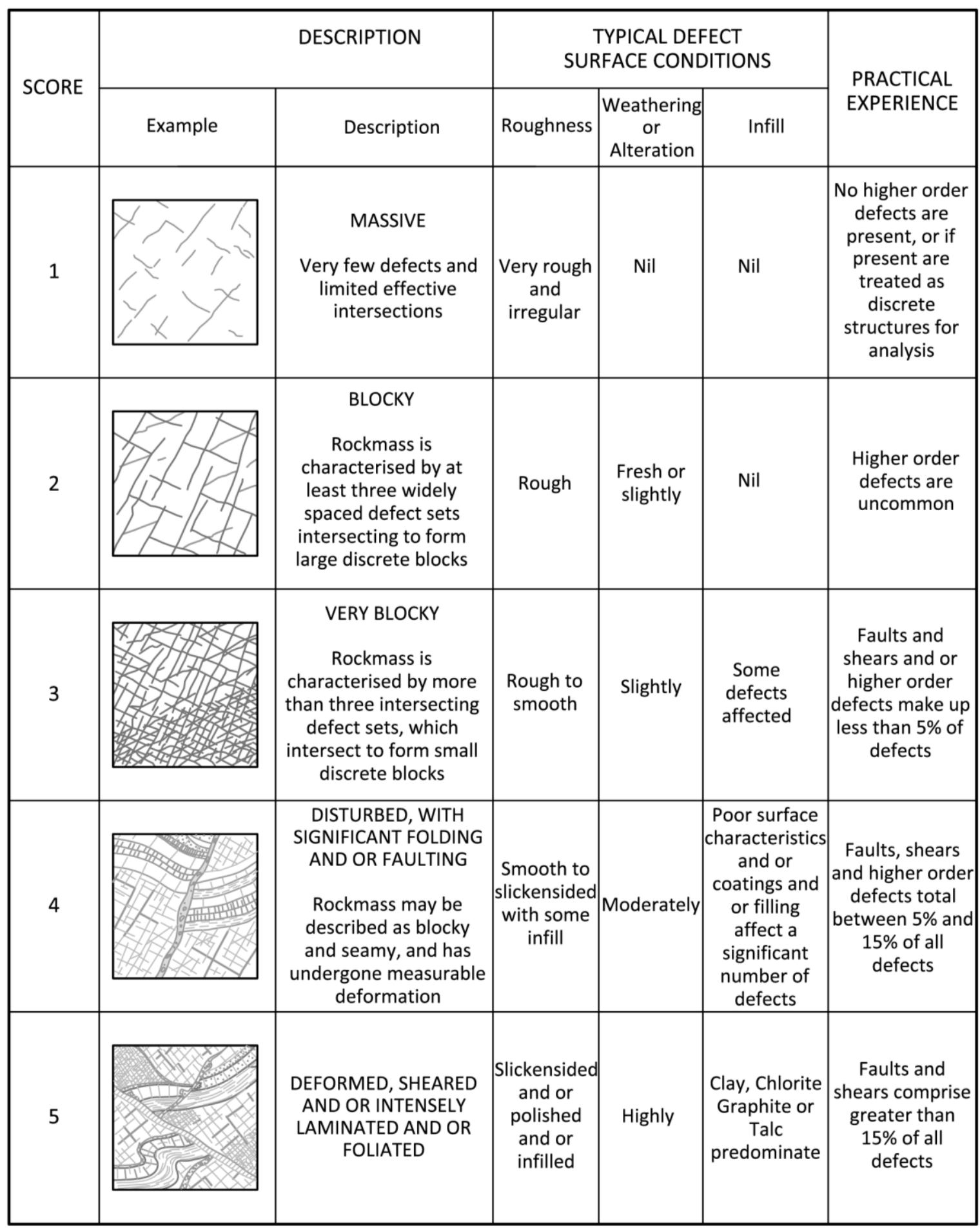

\section{Figure 2 GSPI rock mass classification}

The system is defined in Figure 2 and includes three main columns of descriptors:

1. The rock mass description, with an example illustration and comprising:

a. Massive - very few defects and limited effective defect intersections.

b. Blocky - rock mass contains at least three widely spaced defect sets intersecting to form discrete blocks.

c. Very Blocky - rock mass contains more than three intersecting defect sets, as per Figure 2, forming small discrete blocks. 
d. Disturbed - rock mass contains a significant amount of folding and or faulting and may be described as blocky and seamy, having undergone measureable deformation.

e. Deformed - a sheared and or intensely laminated and or foliated rock mass.

2. Typical defect surface conditions, described with three simple divisions, roughness, weathering and or alteration and infill.

3. It can be very difficult in practice without large exposures, to establish a clear idea of the large scale rock mass character. Hence a column is added with the practical experience in terms of the general percentages of poorer defects that may be experienced in a particular rock mass. This column is useful when dealing with borehole data alone or where this is the main data set available. This general experience indicates that:

a. A very blocky rock mass would typically contain around $5 \%$ or less, of faults or shears or higher order defects.

b. A disturbed rock mass would typically contain between $5 \%$ and $15 \%$ faults shears and or higher order defects.

c. A deformed rock mass typically contains greater than $15 \%$ faults and shears.

To use Figure 2 it is best to start with the example and the simple description. Then check the defect surface conditions, and finally the practical experience may be used to further check or assist judgement in arriving at the right GSPI score. If uncertainty persists then more reliance should be placed on the general character of the defect surfaces.

\subsection{Controlling structure type}

The next question that needs to be answered is

What is the controlling structure type in the rock mass?

Controlling structure means, the dominant structure type in the rock mass, which is likely to control slope performance at the slope scale being assessed. The factors used to assess this question include, continuity and or frequency of occurrence and or the number of structure intersections. However the strength of the different structure types is also very important. For example a closely jointed rock mass may also contain a number of faults and shears. Hence is it the joints or the faults and shears that are the dominant structure type? In order to assess this question reference needs to be made back to the scale of the excavation and the structures it contains, Figure 1 and also Figure 2.

This index should be determined from the factors below in approximate order of decreasing importance:

1. Length or continuity.

2. Strength of the defect surface(s).

3. Frequency of occurrence.

4. Defect intersections.

The selection should start firstly with geological conventions. It is a hierarchical system and should be based on geological conventions of structure hierarchy (Field Geologists Manual (AusIMM, 1995)). However these have been modified based on experience to raise the rating for contacts, unconformities, bedding, foliation and schistosity. This is because the geological experience gained from very large scale exposures as occur in mines, demonstrates that when these features occur in a slope there is a high likelihood the rock mass also includes particular low strength structure parallel features such as bedding plane shears and foliation or schistosity parallel shears. However the bedding, foliation, schistosity or cleavage must comprise actual defects and not simply be a fabric within the intact rock. The general system is illustrated in Figure 3. 


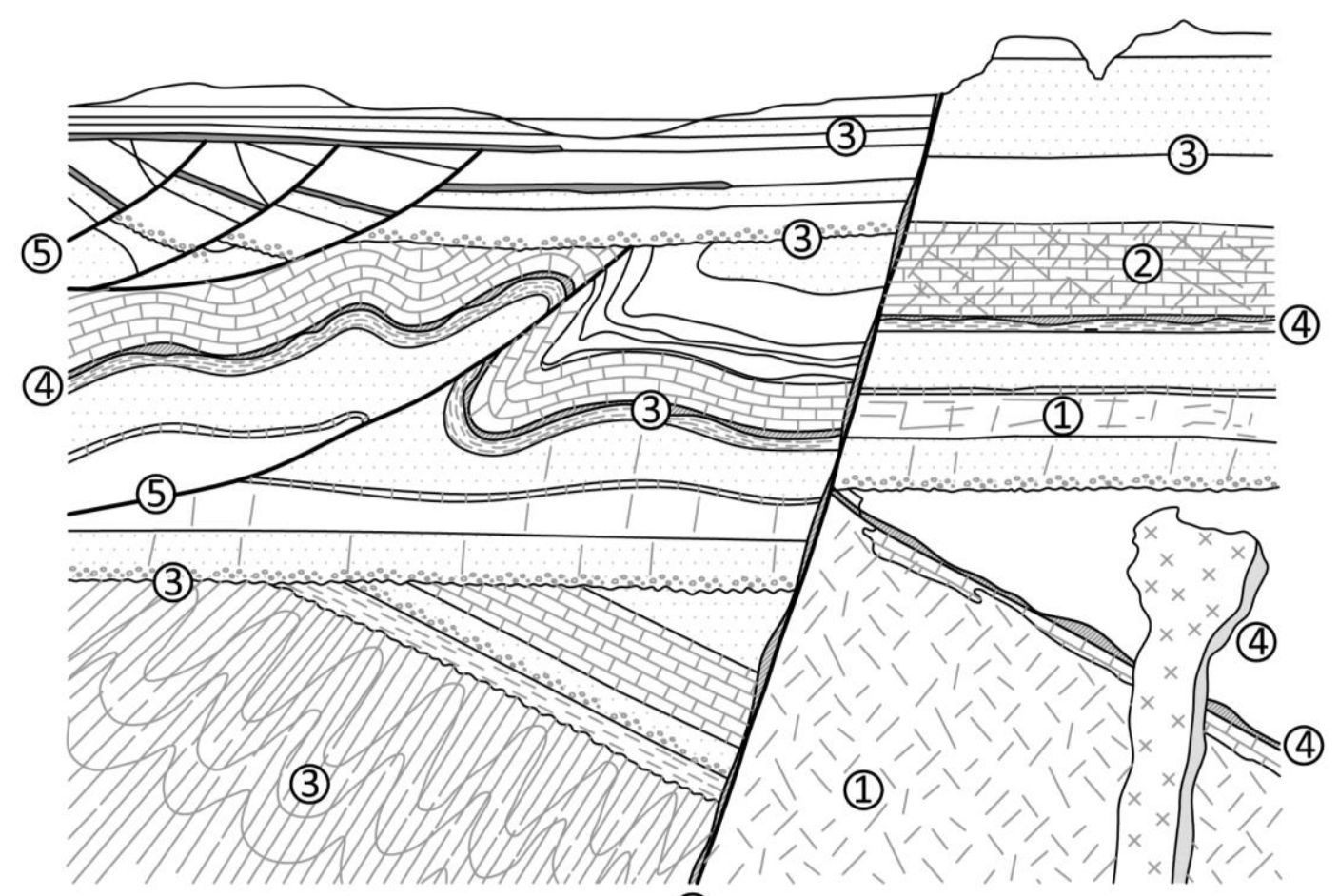

(5)

LEGEND

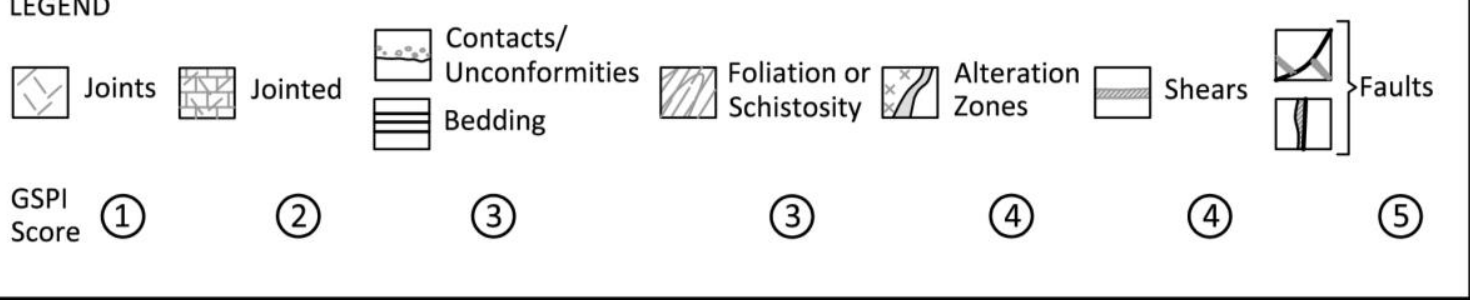

Figure 3 Geological structure hierarchy and GSPI score (after Davis, 1984)

This particular aspect of the system is probably the most difficult to get right in practice. This is demonstrated by the RMR/GSI systems, which rate rock structure as part of the systems but fail to classify or explain how to accurately account for the importance of the different structures types within the rock mass. This almost invariably leads to the minor but statistically more important defects being given undue weighting in the system, to the detriment of those defects that actually control the stability on a larger scale. This is the role of Figure 1 to focus on decision making.

Most rating systems refer simply to defects as joints. However the GSPI refers to defects, which is more important because it is essential as part of the index to differentiate between faults, shears, bedding planes, contacts and joints.

The rating system comprises, in order of increasing importance for or influence on stability:

1. Discontinuous joints, not intersecting.

2. Joints, with at least three intersecting sets.

3. Bedding, foliation, schistosity or cleavage.

4. Shears and or shear and or alteration zones, and or contacts or unconformities sheared joints.

5. Faults. 
The selection must be controlled by evaluation of the factors of most importance for slope scale under consideration. This could be a function of either:

- Length of the structures, where the structures of lowest strength are either:

- Of similar scale to the slope under consideration; or

- Much less than the scale of the slope under consideration.

- The structures are not long, but form a pervasive fabric in the rock mass; and/or

- The structures form a higher than normal percentage of the overall defects within the rock mass.

Experience has shown a key for success is to start by firstly evaluating what are the longest (most continuous) low strength defects in the rock mass. In that regard the concepts in Figures 1 and 3 should be used in conjunction. These defects have to be assessed kinematically according to their possible contribution to degrees of freedom of movement and if this is assessed as unlikely then the next longest structures are assessed in turn. In most instances this process will generally follow the geological structure hierarchy set out above; start by firstly assessing the faults and shears then work progressively though the structures ending with the joints. This rigour will assist in the correct assessment of the controlling defect type.

\subsection{Controlling structure orientation}

These controlling structures then need to be combined with their orientation relative to the slope.

The system is shown in Figure 4. Once the controlling defect set has been selected the next step is assess the dip relative to the slope aspect. In that regard it is very important to be careful about dip direction of the controlling defect set. The standard texts, Wyllie and Mah (2004), use a limiting angle of $\pm 10^{\circ}$ between the dip direction of the structure and the dip direction of the face for plane sliding for the daylighting envelope. However this can be misleading and experience shows that as the intact rock strength decreases and/or the strength of the defects decreases, and/or the dip flattens, then this angle can even approach $\pm 40^{\circ}$. This doesn't mean that plane sliding is necessarily the final mechanism but movement can occur and often other failure mechanisms then take over, for instance one sided wedge sliding. The GSPI subdivisions are:

1. Dipping into the slope but at an angle less than $50^{\circ}$.

2. Parallel to the slope, $\pm 10^{\circ}$.

3. Dipping out of the slope between 0 and $5^{\circ}$.

4. Either out of the slope or dipping steeply into the slope:

a. Dipping out of the slope between 5 and $20^{\circ}$; or

b. Dipping into the slope from 50 to $80^{\circ}$.

5. Dipping out of the slope at greater than $20^{\circ}$.

In order to assist the process some limiting constraints in terms of the dip direction of the structures relative to the slope face are provided in Figure 4. These are for general guidance and should not be taken as absolute design rules. 


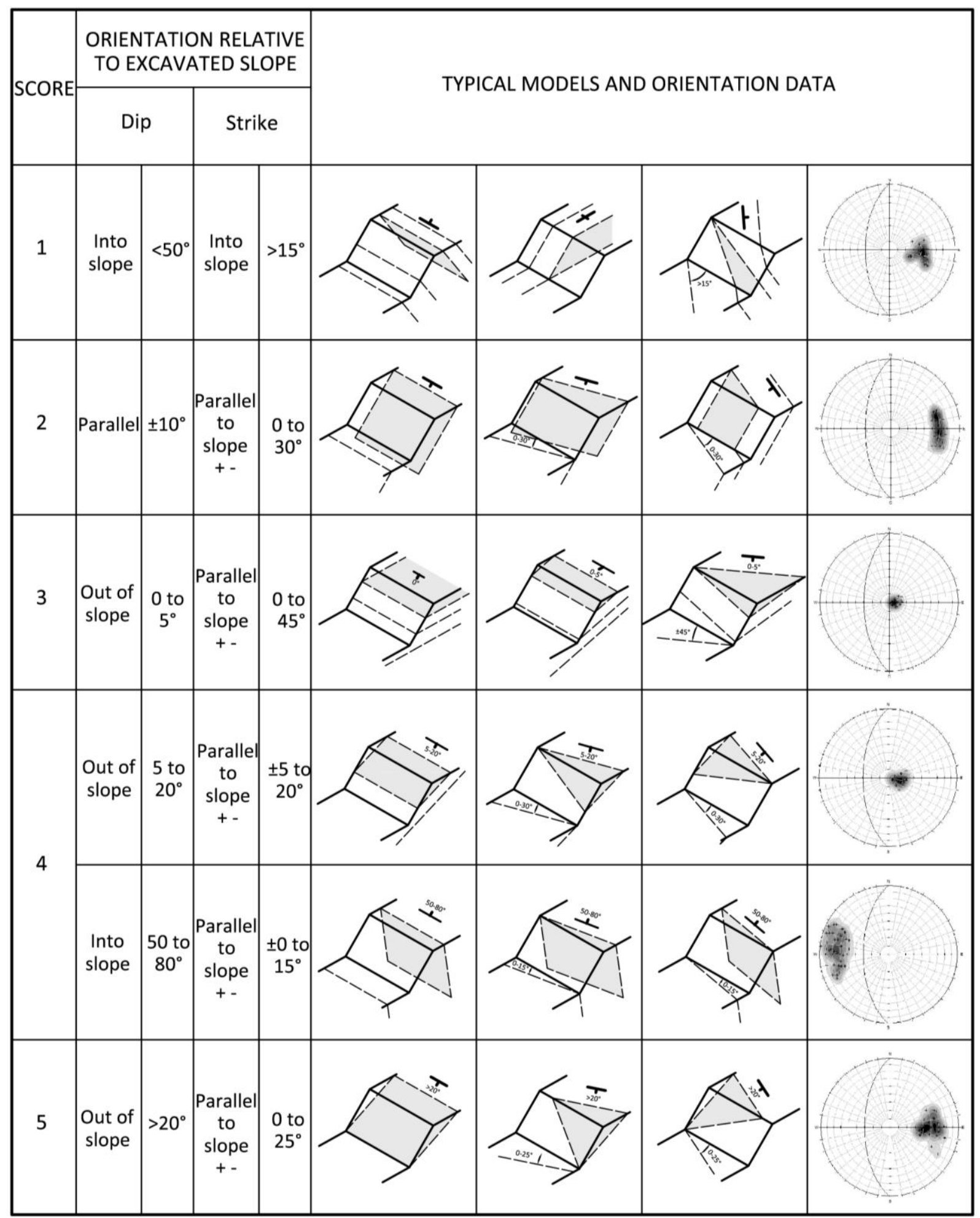

Figure 4 Controlling structure orientation relative to the excavated slope and GSPI score

\subsection{Groundwater conditions}

The groundwater rating system is a combination of three factors:

- The relative groundwater level (or pore pressure) in the slope compared to the slope height.

- The long term groundwater pattern, is it stable, rising or falling.

- The groundwater response pattern to loading from rainfall runoff events. 
Intuitively, most engineers would understand that the higher the water level in the slope the lower the absolute stability. Similarly a falling groundwater level indicates increasing stability, while the opposite, a rising groundwater level usually signals reducing stability. All excavated slopes move, but the magnitude and rate are usually unique to each slope. Experience then demonstrates that as this movement occurs the responses to other factors generally becomes increasingly adverse, including factors such as increasing groundwater rises due to rainfall or the adverse influences linked to nearby stored water bodies (Sullivan, 2007). These responses also usually increase as slopes approach failure. Under these conditions experience shows that groundwater levels usually increase and the impacts become increasingly adverse for stability. Although there is sometimes an intermediate step where there is sufficient movement for groundwater levels to start falling, before the dilation of the rock mass becomes sufficiently large, that the rainfall responses become increasingly larger and the response times shorten.

Although this index is described initially in terms of groundwater level this could also be classified in terms of groundwater pressures. Many rock masses have complex hydrogeological conditions and if groundwater control measures have been implemented there is often some underdrainage. In this situation groundwater pressures below hydrostatic apply. The examples in Figure 5 illustrate this situation.

The GSPI groundwater classifications are, Figure 5:

1. Dry slope, with no significant groundwater present.

2. A low groundwater level relative to the slope height, essentially less than one third of the slope height, and or groundwater pressures less than $25 \%$ of hydrostatic.

3. A groundwater level more than one half of the slope height, but with groundwater levels that are generally falling, and or groundwater pressures less than $50 \%$ of hydrostatic.

4. A groundwater level around two thirds of the slope height and or with groundwater levels that are rising or steady, and or groundwater pressures around $75 \%$ of hydrostatic.

5. A groundwater level equal to or more than two thirds of the slope height and or with significant peak responses to rainfall events, and or groundwater pressures close to hydrostatic.

\subsection{Procedure}

The procedure for estimating the GSPI score comprises:

1. Assess each index individually.

2. In order.

3. In the fixed sequence presented in this paper.

4. Rating each index on the five point rating scale.

5. Then move on to rating the next index.

6. Sum the numbers for the GSPI.

It is important to follow this disciplined approach to try and ensure objectivity. The reason for the regimented approach is to ensure that inherent or intuitive biases do not influence the outcome. This will also try to ensure that the GSPI scores are allocated with careful consideration and judgement using what Kahneman (2011) refers to as the Type 2 mental processes, rather than the quick, intuitive Type 1 system. The point of distinguishing Type 1 and Type 2 systems is that while Type 1 is intuitive and seems natural it is often flawed.

As for all engineering, a very useful cross check at the end of this process is to 'close your eyes' and briefly contemplate whether the assessment seems correct or whether some aspects need to be reconsidered. 


\begin{tabular}{|c|c|c|c|c|c|c|}
\hline \multirow{2}{*}{ SCORE } & \multicolumn{4}{|c|}{ DESCRIPTION } & \multicolumn{2}{|c|}{$\begin{array}{c}\text { ALTERNATE GROUNDWATER } \\
\text { CONDITIONS }\end{array}$} \\
\hline & Condition & Description & $\begin{array}{c}\text { Ground } \\
\text { Water Level } \\
\text { Change }\end{array}$ & $\begin{array}{c}\text { Rainfall } \\
\text { Response }\end{array}$ & $\begin{array}{l}\text { Groundwater } \\
\text { Level }\end{array}$ & $\begin{array}{l}\text { Pore Pressure } \\
\text { Conditions }\end{array}$ \\
\hline 1 & DRY & $\begin{array}{l}\text { No } \\
\text { significant } \\
\text { groundwater }\end{array}$ & & & 3 & $-\sum_{25 \%}^{\mathrm{P}(\mathrm{kPa})}$ \\
\hline 2 & LOW & $\begin{array}{l}\text { Low level } \\
\text { relative to } \\
\text { slope }\end{array}$ & Generally & & & P(kPa) \\
\hline 3 & MODERATE & $\begin{array}{l}\text { Level } \\
\text { approaches } \\
\text { half slope } \\
\text { height }\end{array}$ & $\begin{array}{c}\text { Generally } \\
\text { Falling } \\
\downarrow\end{array}$ & & 3 & $\left.\right|_{<50 \%} ^{\mathrm{P}(\mathrm{kPa})}$ \\
\hline 4 & ELEVATED & $\begin{array}{c}\text { Level around } \\
\text { two thirds of } \\
\text { slope and or } \\
\text { rising levels } \\
\text { and or with } \\
\text { possible } \\
\text { rainfall } \\
\text { response }\end{array}$ & $\begin{array}{c}\text { Steady or } \\
\text { Rising }\end{array}$ & $\begin{array}{l}\text { No } \\
\text { or } \\
\text { Yes }\end{array}$ & 3 & $\stackrel{\mathrm{P}(\mathrm{kPa})}{\mathrm{Hy}}$ \\
\hline 5 & $\begin{array}{c}\text { HIGH TO } \\
\text { FULLY } \\
\text { SATURATED }\end{array}$ & $\begin{array}{l}\text { Essentially a } \\
\text { fully } \\
\text { saturated } \\
\text { slope and or } \\
\text { significant } \\
\text { peak rainfall } \\
\text { reponses }\end{array}$ & & Yes & 3 & ${ }_{100 \%}^{\mathrm{P}(\mathrm{kPa})}$ \\
\hline
\end{tabular}

Figure 5 Groundwater conditions and GSPI score 


\section{Stability and slope performance}

\subsection{Classification}

The classification of stability and performance used to correlate with the GSPI scores comprises:

1. Stable, with no significant failure(s).

2. Rockfall.

3. Bench scale failures - minor.

4. Multiple failures at bench scale.

5. Widespread movement across the whole or a major portion of the slope.

6. Failure.

7. Collapse.

This is a general classification in approximate order of increasing severity or adverse impact. There may be some debate around the ranking of rockfall below minor bench scale failure, but at this stage data was very limited for rockfall and hence it has been included below bench stability.

\section{$7 \quad$ Calibration results}

\subsection{Introduction}

A total of 133 case histories, for which sufficient data was available, have been used for the correlation. These case histories include:

1. Slope heights from 30 to $700 \mathrm{~m}$.

2. Overall slope angles from 19 to $64^{\circ}$.

3. A very wide range of material types:

- Sandstone, siltstone, lignite, oil shale, meta sediments, phyllite, schist, serpentinite, tuff, volcanics, basalt, volcanic breccias, igneous breccias, gabbro, syenite, andesite, porphyry and granite.

4. Intact material strengths (UCS) from 1.5 to $>200 \mathrm{MPa}$.

5. A very wide range of climates from desert to tropics.

6. Excavated slopes in Australia, New Zealand, Pacific, Asia, Africa and South America.

\subsection{Intact strengths}

Figure 6 presents a comparison of the GSPI correlation with slope performance classification using the PSM and ISRM strength classifications. These results show the PSM strength classification has a number of advantages over the ISRM classification, including:

- reduced scatter,

- lower standard deviations for all slope performance classifications; and

- a higher overall correlation coefficient.

It is considered these differences result from the weighting of the PSM rock strength scale towards the lower strength ranges.

The correlation coefficient for the PSM strength classification is $R^{2}=0.86$ which is very reasonable considering the nature of the data and the correlation. 
All further discussions in this paper deal with the PSM classification, however the reader may refer to Figure 6 if the ISRM strength classification is required.
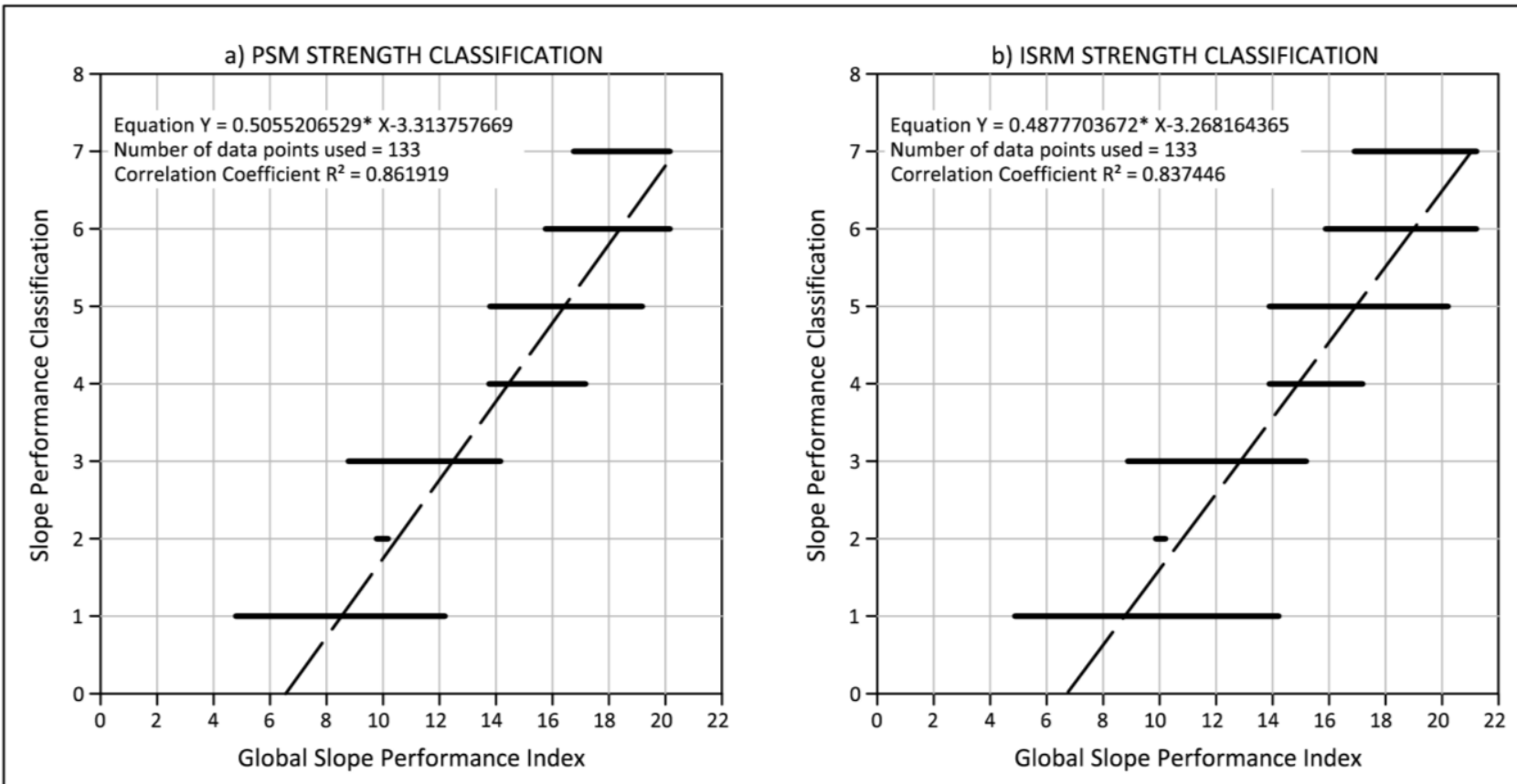

Figure 6 Comparison of results for ISRM and PSM strengths; (a) PSM strengths; and (b) ISRM strengths

\subsection{Results}

The results are presented in Table 5 and summarised in Figure 7, which shows for each slope performance classification:

- the total range,

- the range for \pm one standard deviation; and

- the mean GSPI score.

More detailed correlations and statistics have not been attempted at this stage because some slope performance classifications have low case numbers; for example Rockfall (1), Multiple Bench Failures (10) and Collapse (10). However this will be attempted in a future edition of this paper which will have a more extensive database.

Review of the database did not indicate that any one of the five indices dominated the results in any slope performance classification. The results also generally confirmed that in most instances, higher GSPI scores were generally related to a minimum of three high individual index scores for the Failure (Class 6) and Collapse (Class 7) cases. 


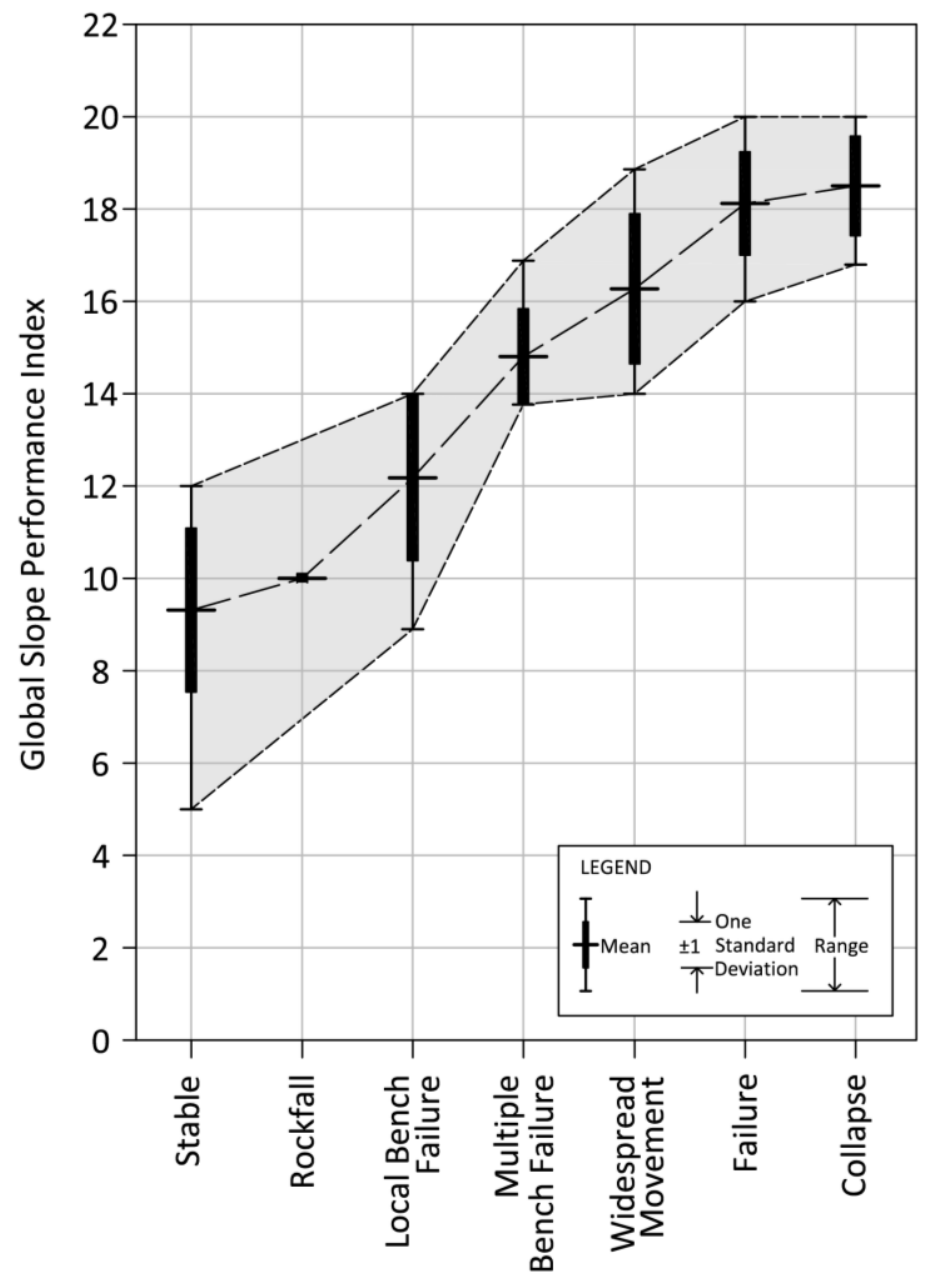

Slope Performance Classification

Figure 7 Correlation of GSPI and slope performance classification

Table 5 Summary correlation results for PSM strengths

\begin{tabular}{|c|c|c|c|c|c|c|c|}
\hline \multirow{2}{*}{$\begin{array}{c}\text { Slope } \\
\text { Performance } \\
\text { Class No. }\end{array}$} & \multirow[t]{2}{*}{ Description } & \multirow{2}{*}{$\begin{array}{l}\text { Number } \\
\text { of Cases }\end{array}$} & \multicolumn{5}{|c|}{ Results } \\
\hline & & & Minimum & Maximum & Mean & Median & Deviation \\
\hline 1 & Stable & 45 & 5 & 12 & 9 & 10 & 1.78 \\
\hline 2 & Rockfall & 1 & 10 & 10 & 10 & 10 & NA \\
\hline 3 & $\begin{array}{l}\text { Local bench } \\
\text { failures }\end{array}$ & 16 & 9 & 14 & 12 & 13 & 1.80 \\
\hline 4 & $\begin{array}{c}\text { Multiple } \\
\text { bench failures }\end{array}$ & 10 & 14 & 17 & 15 & 15 & 1.03 \\
\hline 5 & $\begin{array}{l}\text { Widespread } \\
\text { movement }\end{array}$ & 15 & 14 & 19 & 16 & 16 & 1.62 \\
\hline 6 & Failure & 36 & 16 & 20 & 18 & 18 & 1.12 \\
\hline 7 & Collapse & 10 & 17 & 20 & 19 & 19 & 1.08 \\
\hline
\end{tabular}




\subsection{Trends}

There were two other overall trends present in the data and these are illustrated in Figure 8.

1. Increasing GSPI scores above the generally stable cases, of Stable (Class 1), Rockfall (Class 2) and Minor Bench Failures (Class 3) were associated with an increasing influence of:

a. Rock mass character (that is deformation); and

b. The controlling structure types.

2. Increasing GSPI scores above the widespread movement of the slope (Class 5) to Failure (Class 6 ) and Collapse (Class 7) were associated with an increasing influence of:

a. Groundwater.

b. The orientation of the controlling structure types relative to the slope face.

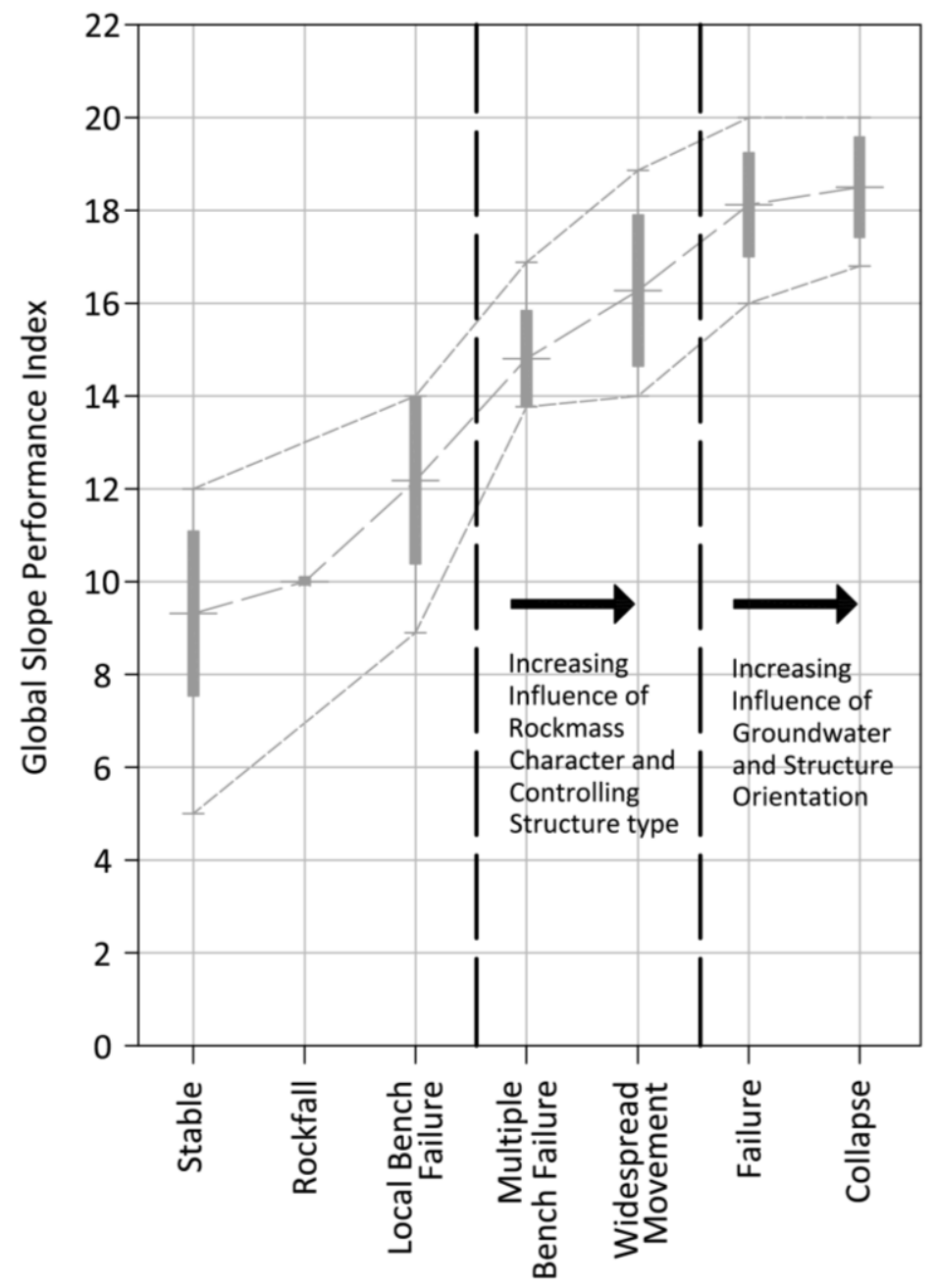

Slope Performance Classification

\section{Figure 8 GSPI trends}

\section{Use of GSPI}

The GSPI system is relatively simple to use:

1. Determine the individual GSPI scores for each index using Table 4 and Figures 1 to 5.

2. Follow the procedure in Section 5.10 . 
3. Refer to the detailed discussion for the indices if some uncertainty exists.

4. Sum the individual end scores for each index to determine the total GSPI score.

5. Use Figure 7 to indicate the likely slope performance classification, which then defines the hazard(s), for example:

a. A GSPI score of 18 indicates a reasonable likelihood of slope failure, with some chance of complete collapse; or

b. A GSPI score of 16 indicates a reasonable likelihood of widespread movement of the slope, with a low likelihood of failure, provided conditions do not deteriorate due to the movement.

6. Based on the outcomes from Step 4, assess the consequences of the hazards defined there for the particular slope geometry and setting.

7. Undertake review and investigations, including:

- All monitoring.

- The geotechnical and groundwater models for the area.

- Assess the need for additional investigations.

\section{Ground control management plan}

Ground Control Management is essential good practice in mining and a Ground Control Management Plan (GCMP) is now standard practice in the industry. The GSPI should form part of the GCMP. The various slopes in the mine may be quickly assessed using the GSPI, benchmarked for potential stability issues and risk rated according to whatever local risk rating system is used in the mine. All monitoring and or investigations may then be set out accordingly.

\section{Target audience}

The GSPI has a number of target audiences, including:

- The young professional with limited experience, but who is tasked with managing a mine or an excavation to its successful completion.

- The operator, who when faced with evidence of a potential problem with a slope is seeking a 'reality check'.

- The experienced professional who after a design is completed requires confidence in the outcomes of the more detailed technical evaluations.

- All practitioners, who when faced with the questions that invariably arise about one or more technical elements of a slope, needs a simple practical way of evaluating whether what they are seeing in the data is important for performance and risk.

\section{Conclusions}

This paper draws together the cumulative knowledge from decades of experience to provide a simple empirical system for assessing the likely performance and risks associated with excavated slopes. The system is applicable to all slopes excavated in rock in both the civil and mining industries.

The GSPI comprises a simple algorithm that sums the scores from the separate ranking of five indices. The indices are based on intact strength, geological structure and groundwater. Simple guidelines are provided for each index which allows the relative contribution of the index to be rated or scored with a one to five linear numerical scale. All indices have equal weighting, because experience has shown that for any one 
particular slope in any particular geological and or geotechnical setting any one or a number of the five indices may be critical.

Clearly adverse stability outcomes with excavated slopes carry risk to the project or mine. The risk will be a particular function of the type, size and location of the potential hazard within the project or mine and will be fairly unique to each case. In general the risk can be assessed and managed if the hazard is able to be identified beforehand and experience is available to highlight its type and or size. The GSPI scores have been linked to the actual performance of 133 case studies of excavated slopes. These case studies cover the full range of operational performances from stable to complete collapse of a large portion of the slope.

A very good correlation has been demonstrated between the GSPI score and the slope performance. The intent of the GSPI is not to provide a single number that may be directly linked to a precise stability performance outcome. An adverse potential stability performance represents a hazard and a potential risk to the project or operation. However, not all hazards manifest themselves in adverse risk outcomes.

The GSPI provides a simple system for:

- Firstly identifying the potential for an adverse stability outcome, the event or hazard.

- Secondly identifying generally what the event or hazard may entail either as a single hazard or range of possible outcomes.

- Thirdly providing guidance in terms of potential scales.

The identification of a potential event or hazard would then be the basis for:

1. A review of all the monitoring data.

2. A more detailed groundwater and geotechnical review.

3. Assessment of the need for additional investigations.

This would also, in the case of a mine, form part of the GCMP process.

\section{References}

Attewell, P.B. and Farmer, I.W. (1975) Principles of Engineering Geology, John Wiley \& Sons, New York.

AusIMM (1995) Field Geologists Manual, Monograph 9.

Australian Standards (1993) Geotechnical site investigations, AS 1726-1993.

Bieniawski, Z.T. (1976) Rock mass classification in rock engineering, in Proceedings Symposium on Exploration for Rock Engineering, Z.T. Bieniawski (ed), 1-5 November 1976, Johannesburg, South Africa, Balkema, Rotterdam, pp. 97-107.

Bieniawski, Z.T. (1989) Engineering rock mass classifications, John Wiley \& Sons, New York.

CANMET (1977) Canada Centre for Mineral and Energy Technology, Pit slope manual, chapter 2 structural geology, G. Herget (ed), CANMET REPORT, pp. 88.

Chen, Z. (1995) Recent developments in slope stability analysis, in Proceedings 8th International Congress on Rock Mechanics, Vol. 3, 25-30 September 1995, Tokyo, Japan, International Society for Rock Mechanics, pp. 1,041-1,048.

Davis, G.H. (1984) Structural geology of rocks and regions, John Wiley \& Sons, New York.

Dawes, R.M. (1979) The robust beauty of improper linear models in decision making, American Psychologist, 34, pp. 571-582.

Douglas, K.J. (2002) The shear strength of rock masses, PhD thesis, The University of New South Wales, Kensington, Australia.

Driscoll, R. and Simpson, B. (2001) EN1997 Eurocode 7: Geotechnical design, ICE - Civil Engineering, Thomas Telford Ltd, Vol. 144, Issue 6, pp. 49-54.

Geological Society, Engineering Geology Working Group (1977) The description of rock masses for engineering purposes, Quarterly Journal of Engineering Geology and Hydrogeology, Geological Society of London, Vol. 10, pp. 355-388.

Haines, A. and Terbrugge, P.J. (1991) Preliminary estimation of rock slope stability using rock mass classification systems, in Proceedings 7th International Society Rock Mechanics, 16-20 September 1991, Aachen, Germany, International Society for Rock Mechanics, Vol. 2, pp. 887-892.

Hartford, D.N.D. (1998) This dam risk business - The challenge of implementation - managing the risks of risk assessment, ANCOLD Bulletin, Australian National Committee on Large Dams, No. 110.

Hoek, E., Kaiser, P.K. and Bawden, W.F. (1995) Support of Underground Excavations in Hard Rock, Balkema, Rotterdam.

ISRM (1978) Suggested methods for the quantitative description of discontinuities in rock masses, International Journal of Rock Mechanics and Mining Sciences \& Geomechanics Abstracts, Elsevier, Vol. 15, pp. 319-368.

ISRM (2007) The complete ISRM suggested methods for rock categorisation, testing and monitoring: 1974-2006, R. Ulusay and J.A. Hudson (eds), International Society for Rock Mechanics Turkish national Group, Ankara, Turkey. 
Kahneman, D. (2011) Thinking, fast and slow, Penguin, London.

Laubscher, D.H. (1977) Geomechanics classification of jointed rock masses - mining applications, Transactions of the Institution of Mining and Metallurgy, Section A, Mining Industry, Vol. 86 (Jan), pp. A1-A8.

Laubscher, D.H. (1990) A geomechanics classification system for the rating of rock mass in mine design, Journal of the South African Institute of Mining and Metallurgy, Southern African Institute of Mining and Metallurgy, Vol. 90 (10), pp. 257-273.

Lin, Y. (1998) An introduction of the Chinese standard for engineering classification of rock mass, Advances in Rock Mechanics, World Scientific Publishing Co., Singapore, pp. 317-327.

Marinos, P. and Hoek, E. (2000) GSI: A geologically friendly tool for rock mass strength estimation, in Proceedings GeoEng 2000 Conference, 19-24 November 2000, Melbourne, Australia, Technomic Publishing Company, Lancaster, Vol. 1, pp. $1422-1440$.

McMahon, B.K. (1985) E.H. Davis Memorial Lecture: geotechnical design in the face of uncertainty, Australian Geomechanics Journal, Australian Geomechanics Society, Issue 10, pp. 7-19.

Orr, C.M. (1992) Assessment of rock slope stability using the rock mass rating (RMR) system, The AusIMM Proceedings, Australasian Institute of Mining and Metallurgy, Carlton, Vol. 297(2), pp. 25-29.

Robertson, A.M. (1988) Estimating weak rock strength, SME Annual Meeting, Tuscon, Arizona, Society of Mining Engineers, Preprint No. 88-145, pp. 1-5.

Romana, M. (1985) New adjustment ratings for application of Bieniawski classification to slopes, in Proceedings International Symposium on the Role of Rock Mechanics, 2-4 September 1985, Zacatecas, Mexico, International Society for Rock Mechanics, Lisbon, pp. 49-53.

Royal Society (1992) Science, policy and risk, Royal Society Publishing, London.

Selby, M.J. (1980) A rock mass strength classification for geomorphic purposes: with tests from Antarctica and New Zealand, Zeitschrift fur Geomorphologie, N.F., Schweizerbart Science Publishers, Vol. 24 (1), pp. 31-51.

Sullivan, T.D. (1994) Mine slope design - The chances of getting the answer right and the risk of getting it wrong, in Proceedings 4th Large Open Pit Mining Conference, 5-9 September 1994, Perth, Australia, South African Institute of Mining and Metallurgy, Johannesburg.

Sullivan, T.D. (2006) Pit slope design and risk - A view of the current state of the art, in Proceedings Symposium Series S44, Stability of rock slopes in open pit mining and civil engineering situations, 3-6 April 2006, Johannesburg, South Africa, South African Institute of Mining and Metallurgy, Cape Town.

Sullivan, T.D. (2007) Hydromechanical coupling and pit slope movements, Keynote Lecture, in Proceedings International Symposium on Rock Slope Stability in Open Pit Mining and Civil Engineering (Slope07), Y. Potvin (ed), 12-14 September 2007, Perth, Australia, Australian Centre for Geomechanics, Perth, pp. 3-43.

Terzaghi, K. and Peck, R.B. (1967) Soil mechanics in engineering practice, Second Edition, John Wiley \& Sons, New York.

Ünal, E. (1996) Modified rock mass classification: M-RMR system, milestones in rock engineering, The Bieniawski Jubilee Collection, Balkema, Rotterdam, pp 203-223.

Wyllie, D.C. and Mah, C.W. (2004) Rock Slope Engineering: Civil and Mining, 4th edition, Spoon Press. 